\title{
PSINSAR COHERENCE BASED DISPLACEMENT ANALYSIS OF KRISHNA DELTA USING SENTINEL-1 INTERFEROMETRIC WIDE SWATH DATA
}

\author{
Pratyusha Gonnuru ${ }^{1, *}$, Shashi Kumar ${ }^{2}$, Senthil Kumar ${ }^{1}$ \\ ${ }^{1}$ Centre of Space Science and Technology Education in Asia and the Pacific (CSSTEAP) Dehradun, India - \\ pratyusha963@gmail.com, senthil@iirs.gov.in \\ ${ }^{2}$ Photogrammetry and Remote Sensing Department Indian Institute of Remote Sensing Dehradun, India - shashi@iirs.gov.in
}

Commission V, SS: Disaster Monitoring, Damage Assessment and Risk Reduction

KEY WORDS: PsInSAR, Permanent Scatter Candidates, C-band Interferometric data, Krishna Delta, PS coherence Map

\begin{abstract}
:
The problem of decorrelation leading to loss of coherence has been a major source of concern to identify the various problems of erosion and deposition in delta. In this study, Permanent Scatter Interferometric SAR (PsInSAR) technique was used to identify the Permanent Scatter Candidates (PSCs) to explore its potential in identifying displacement based on coherence of various features in delta during the dry and wet periods. PSCs are coherent over interferograms acquired during different time periods. The study was conducted using Sentinel-1 C-band Interferometric Wide (IW) swath datasets acquired from 25 $5^{\text {th }}$ October 2016 to $10^{\text {th }}$ June 2017 over Krishna Delta. The datasets were deramped and stitched prior to co-registering the master and slave images. Interferograms were generated, phase unwrapped and filtered after which the PSCs were identified based on Amplitude Stability index. The problem of tropospheric phase delay causing decorrelation was removed based on the difference in the phase residual of the connected PSCs. Ps coherence map was generated showing coherence as low as 0.28 to 0.38 in mangroves due to volume decorrelation and 0.5 to 0.85 in village areas. A prominent feature, vernal pool exhibited high variation in coherence ( 0.28 to 0.45$)$ depending on monsoon or summer season. An integrated cumulative displacement map was generated indicating the areas where erosion and deposition has taken place and these depositional values of certain deltaic features were in conjunction with coherence.
\end{abstract}

\section{INTRODUCTION}

Deltas are the major repositories of sediments brought about by the rivers. Delta ecosystem is useful because it supports flora and fauna, agriculture and fishing. They are economically viable as they are hubs for $\mathrm{t}^{1}$ rade (Erban, Gorelick, \& Zebker, 2014) . Remote Sensing plays a vital role in monitoring the problems such as minimum accessibility in deltas. Previous studies on deltas were conducted using optical remote sensing techniques (Anthony et al., 2015; Gamage \& Smakhtin, 2009; Nageswara Rao et al., 2012). Conventional optical imaging techniques have certain disadvantages in comparison to microwave Synthetic Aperture Radar Remote sensing techniques, in its ability to penetrate through clouds and obtain data in all weather conditions. Also, it has the advantage of imaging during day as well as at night (Lee \& Pottier, 2009). Interferometric Synthetic Aperture Radar (InSAR) deals with capturing images from two different locations at the same time or during different times (Bamler \& Hartl, 1998). Several studies were conducted previously in deltas using SAR Interferometry (Hall-Atkinson \& Smith, 2001; Wang et al., 2012). Previous studies conducted using InSAR in Krishna Delta have shown the ability of radar imaging for mapping the erosional and depositional changes ( Gonnuru \& Kumar, 2018). However, the movement of scatterers in various resolution cells during different interferometric acquisitions leads to the problem of decorrelation (Pratyusha Gonnuru \& Kumar, 2018; A. J. Hooper, Segall, \& Zebker, 2006; A. Hooper, Segall, \& Zebker, 2007). This problem is more prominent in deltaic features as they are less coherent due to the difference in scattering properties of the features between SAR acquisitions. This paper describes the use of an advanced SAR Interferometric technique- Permanent Scatter Interferometric SAR (PsInSAR)

\footnotetext{
${ }^{*}$ Corresponding Author
}

for coherence based displacement analysis of different deltaic features. This technique helps to identify the Permanent scatterer candidates with high coherence in the interferograms acquired during the dry and wet periods after estimating and removing the atmospheric phase screen error. The study primarily deals with exploring the potential of PsInSAR for mapping the displacement observed with respect to soil erosion and deposition that has taken place in different features of Krishna Delta.

\section{STUDY AREA AND DATASET}

\subsection{Study Area}

The study area chosen for the present study is Krishna Delta extending from $3^{\circ} 17^{\prime}$ to $81^{\circ}$ ' East to $13^{\circ} 10^{\prime}$ and $1922^{\prime}$ North in Krishna District of Andhra Pradesh, India. The study area is shown below in Figure 1.

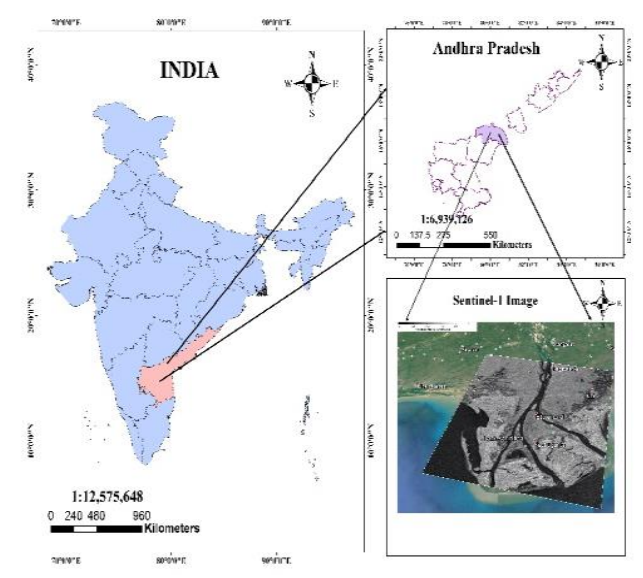

Figure 1: Map showing the Study Area- Krishna Delta 
Topographically, the Delta is divided into Eastern, Western and the landward side. Its geomorphological significance owes to its different landforms. The delta is characterised by mangroves, mudflats, vernal pools and aquaculture ponds (Farooqui, 2010). The presence of mangrove vegetation and certain features like aquaculture ponds is a major reason for the loss of coherence in the delta.

\subsection{Dataset}

The dataset used for Krishna Delta is Sentinel-1 in C-band. 13 datasets were from October 2016 to April 2017 were acquired in Terrain Observation with Progressive Scans SAR (TOPSAR) Interferometric wide swath (IW) mode. IW mode acquires data in three sub-swaths using TOPSAR. TOPSAR has an advantage as it minimises the scalloping effect and signal to noise ratio (SNR) and produces a uniform image quality (Moreira et al., 2013; Yague-Martinez et al., 2016).

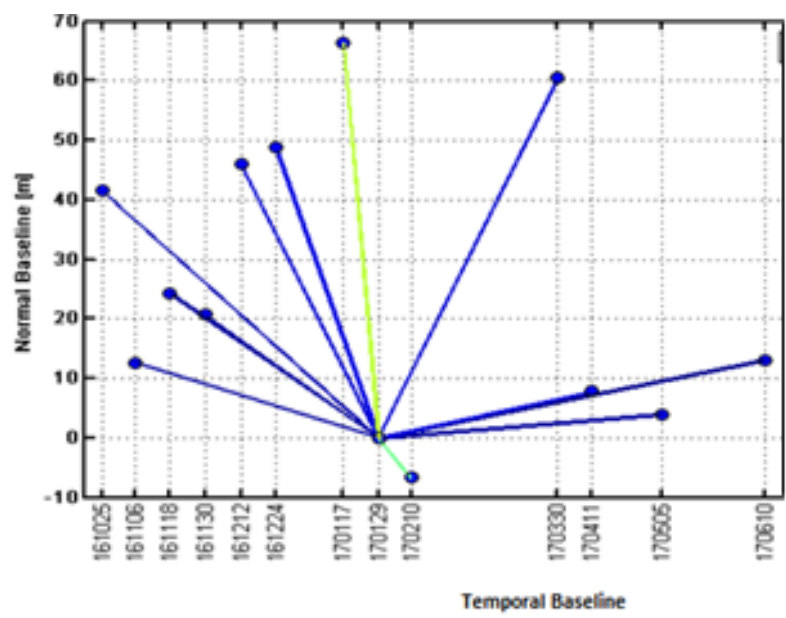

Figure 2: Baseline Dataset information of the acquired Sentinel1 datasets

Figure 2 represents the dataset information. The master image chosen was $29^{\text {th }}$ January 2017 . Normal baseline information is shown on $\mathrm{Y}$-axis and the temporal baseline information on $\mathrm{X}$ axis.

Table 1 represents the information about the Interferometric datasets of Sentinel-1 acquired over Krishna Delta. 13 datasets are shown from $25^{\text {th }}$ October 2016 to $10^{\text {th }}$ June 2017.

Table 1: Sentinel-1 dataset information

\begin{tabular}{|c|c|c|c|}
\hline $\begin{array}{c}\text { Date of } \\
\text { acquisition }\end{array}$ & Polarisation & $\begin{array}{c}\text { Perpendicular } \\
\text { Baseline }\end{array}$ & $\begin{array}{c}\text { Temporal } \\
\text { Baseline }\end{array}$ \\
\hline $\begin{array}{c}25^{\text {th }} \text { October, } \\
2016\end{array}$ & VV & 41.56 & -95.99 \\
\hline $\begin{array}{c}6^{\text {th }} \text { November, } \\
2016\end{array}$ & VV & 12.61 & -83.99 \\
\hline $\begin{array}{c}18^{\text {th }} \\
\text { November, } \\
2016\end{array}$ & $\mathrm{VV}$ & 24.22 & -71.99 \\
\hline $\begin{array}{c}30^{\text {th }} \\
\text { November, } \\
2016\end{array}$ & $\mathrm{VV}$ & 20.65 & -59.99 \\
\hline
\end{tabular}

\begin{tabular}{|c|c|c|c|}
\hline $\begin{array}{c}12^{\text {th }} \\
\text { December, } \\
2016\end{array}$ & VV & 45.96 & -47.99 \\
\hline $\begin{array}{c}24^{\text {th }} \\
\text { December, } \\
2016\end{array}$ & VV & 48.72 & -35.99 \\
\hline $\begin{array}{c}17^{\text {th }} \\
\text { January,2017 }\end{array}$ & VV & 66.38 & -11.99 \\
\hline $\begin{array}{c}29^{\text {th }} \\
\text { January,2017 }\end{array}$ & VV & 0 & 0 \\
\hline $\begin{array}{c}10^{\text {th }} \text { February, } \\
2017\end{array}$ & VV & -6.7 & 11.99 \\
\hline $\begin{array}{c}30^{\text {th }} \text { March, } \\
2017\end{array}$ & VV & 60.43 & 60.53 \\
\hline $\begin{array}{c}11^{\text {th }} \text { April, } \\
2017\end{array}$ & VV & 7.81 & 72.56 \\
\hline $5^{\text {th } \text { May, 2017 }}$ & VV & 3.96 & 96.34 \\
\hline $\begin{array}{c}10^{\text {th }} \\
\text { June,2017 }\end{array}$ & VV & 13.11 & 132.1 \\
\hline
\end{tabular}

\section{METHODOLOGY}

The methodology adopted to process Sentinel-1 datasets using PsInSAR technique is described below in Figure 3.

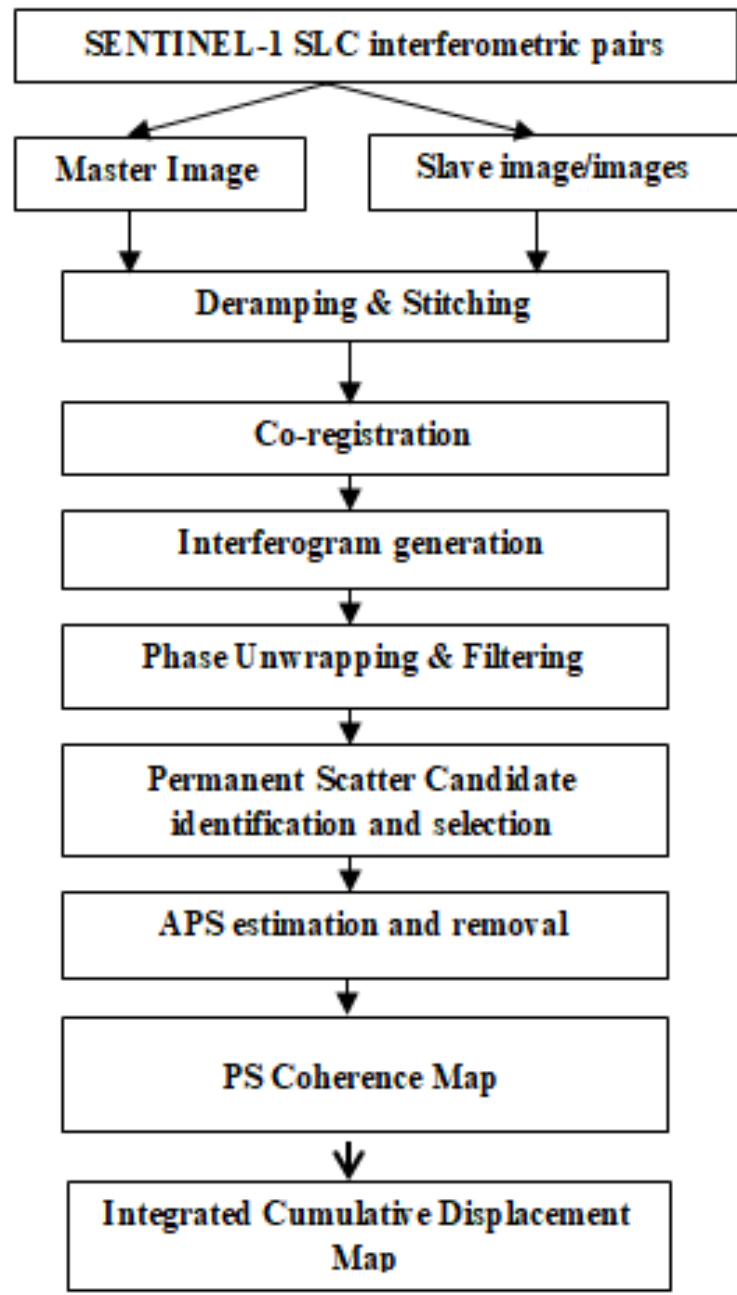

Figure 3: Methodological flow diagram 


\subsection{Deramping and Stitching}

In TOPSAR Interferometric wide swath mode, there is a shift in the Doppler centroid frequency of each burst in the azimuth direction that leads to an introduction of a residual phase term. In order to compensate for the phase term which exhibits quadratic variability in the azimuth causes distortions in the interferogram 'deramping 'was performed (Grandin, 2015)

$$
s_{\text {deramp }}(\eta, \tau)=\left\{-j \pi k_{t}(\tau)\left(1-\eta_{\text {ref }}(\tau)^{2}\right)\right\}
$$

where $\tau$ is range time

$\eta$ is azimuth time

$\eta$ ref is the reference time

To compensate for the slight shift in the overlap between the bursts in the azimuth direction, the bursts were stitched. This step was done after deramping to produce a continuous image (Grandin, 2015)

$$
\Delta \mathrm{p}^{\mathrm{i}}=\frac{\mathrm{n}_{0}{ }^{1}-\mathrm{n}_{0}{ }^{\mathrm{l}-1}}{\mathrm{q}-\mathrm{N}_{\mathrm{bu}}{ }^{\mathrm{i}}}
$$

where $\quad i$ is the burst number

$$
\Delta p^{\mathbb{1}} \text { is the azimuth shift }
$$

$n_{0}{ }^{\mathbb{1}}$ is the current burst

$n_{0}{ }^{\mathbb{I}-1}$ is the previous burst

$\mathrm{q}$ is the sampling interval

$N_{b u s}{ }^{i}$ is the number of samples within the present burst
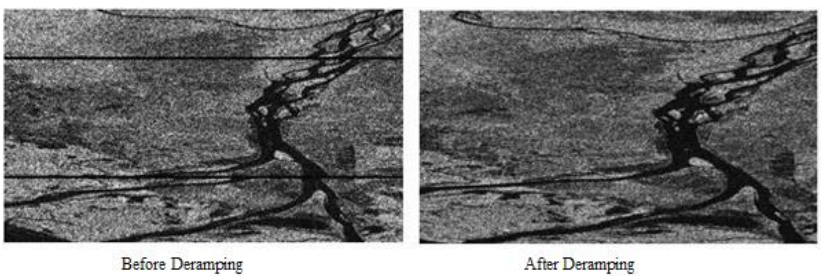

Figure 4: Images of Sentinel-1 TOPSAR dataset before and after deramping

Figure 4 shows the deramped images of Sentinel- 1 datasets. The image on the left shows the study area before deramping. Image on the right shows the study area image after deramping, in which the horizontal lines are removed. It is the image obtained after processing each burst of sub-swaths separately.

\subsection{Co-registration}

After deramping, co-registration was done by matching the corresponding pixels between the master and slave images. Coregistration of the images was implemented in two ways, coarse and fine co-registration. Coarse co-registration was done at pixel level followed by fine co-registration by matching the subpixel of master image with sub-pixel of slave image.

\subsection{Interferogram generation}

After co-registering the master and slave images, interferograms were generated by computing their hermitian product. The interferograms formed indicated the difference in phase between co-registered master and slave images. This phase difference is due to the topography and can be seen in the form of fringes on the interferogram. The convention for the generation of interferogram is given below (Perissin, 2016):

$$
\text { int }_{(\mathrm{i} i \mathrm{k})}=\mathrm{Img} \times \mathrm{Img}_{\mathrm{k}}^{*}
$$

Where int is the interferogram generated between images $\mathrm{i}$ and $\mathrm{k}$

Img is the complex Master image

Imgk is the complex conjugate slave image

\subsection{Phase unwrapping and Filtering}

As the terrain height increases, the phase values are wrapped between 0 and $2 \pi$ radians and repeat in cycles. This phase of the interferogram was unwrapped. Then, the absolute phase was determined from the relative phase of the interferogram which was done by adding an integer multiple of $2 \pi$ to the fringes of the wrapped interferogram. The unwrapped phase is given as (Hartl, 1998)

$$
\emptyset_{\text {unw }}=\emptyset_{\text {wrapped }}+2 \mathrm{~nm}
$$

$$
\begin{aligned}
& \text { where } \emptyset_{w w} \text { is the phase obtained after unwrapping } \\
& \emptyset_{w} \text { is the wrapped phase } \\
& \mathrm{n} \text { is a positive integer }
\end{aligned}
$$

The phase unwrapped interferogram was filtered to remove noise contributions from different sources present in a resolution cell. Goldstein modified filtering technique was used for this purpose.
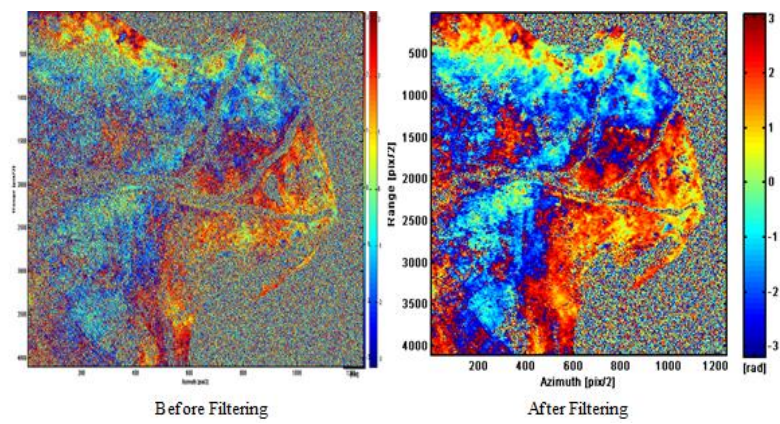

Figure 5: Phase Unwrapped Interferogram

The phase unwrapped interferograms generated before and after filtering is represented in Figure 5. The image on the right is obtained after applying Goldstein modified filter. The phase values range from -3 to 3 radians. It was observed that the phase unwrapped interferogram before filtering shows more phase noise, especially in sea. The fringe patterns are enhanced and clearly observed after filtering. The minimized noise after filtering clearly shows similar phase fringes in mangroves. Also, in urban regions where there are no prominent changes observed during two SAR acquisitions, the phase value is high around 2.5 indicating that the two SAR images are in phase.

\subsection{Permanent Scatter Candidate identification and selection}

The permanent scatter candidates (PSCs) were selected based on amplitude stability index. A threshold of 0.75 as chosen and scatterers having amplitude above this were chosen as permanent scatterers as they are coherent in all the SAR images acquired during different time periods. The points having low to high amplitude stability were overlaid on Google Earth as shown in Figure 6. The permanent scatter points having stable amplitude in all the SAR images acquired from October 2016 to November 2017 are identified and shown on Google Earth. 


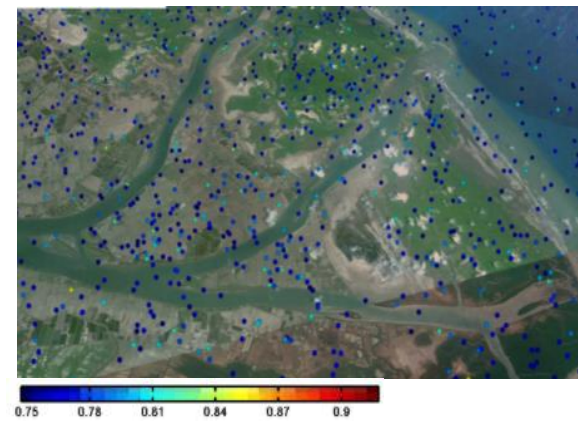

Figure 6: Amplitude stability index image of Krishna Delta

The colour bar shows the points having an amplitude stability of 0.75 an above. Less number of points are identified in mangrove swamps, vernal pool and aquaculture ponds since these points have less reflectivity when compared to the reflectivity obtained from permanent structures like roads, buildings.

\subsection{Atmospheric Phase Screen (APS) Removal}

After the selection of PSCs, the tropospheric phase delay causing Atmospheric Phase Screen (APS) was removed for each image obtained during the time of SAR acquisition. The Atmospheric changes causing phase delay were analysed and estimated based on the variation in the phase residuals between the connected PSCs.

\subsection{PS Coherence Map}

After identifying the PS candidates and removing the atmospheric phase screen error, the amount of correlation between the PSCs in different interferograms was estimated. A PS coherence map was generated by analysing the data over different time periods.

\section{RESULTS AND DISCUSSION}

\subsection{Coherence images overlaid on Google Earth}

The coherence values varied from 0 to 1 depending on the type of scatterers and seasonal variations.

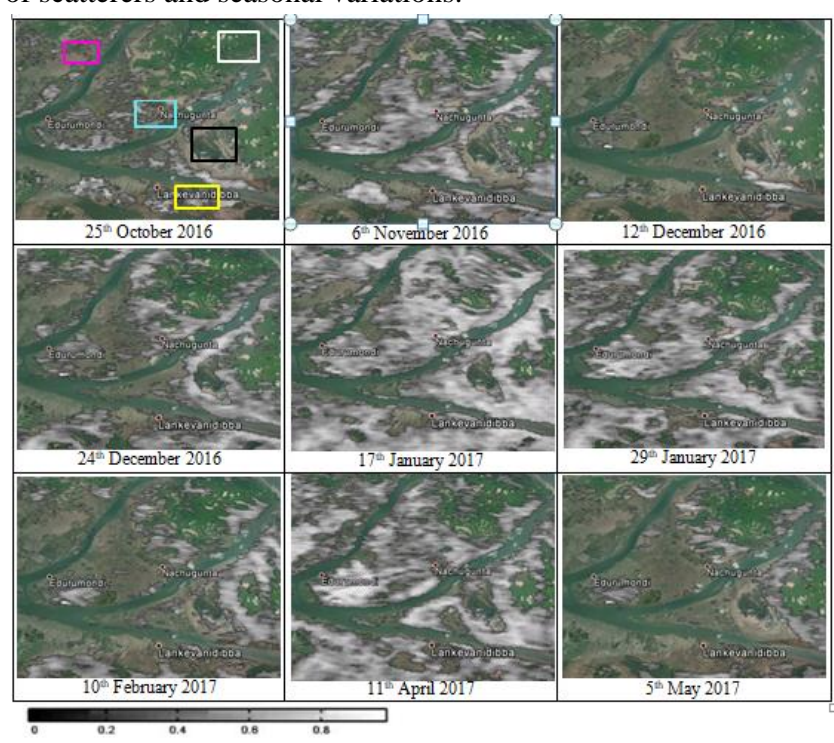

Figure 7: Coherence images overlaid on Google Earth

Low coherence values were observed for areas showing the presence of water. Coherence was high for the permanent structures like buildings, roads, wells, etc. Mangrove swamps and vernal pool showed varied coherence depending on the seasonal variation, i.e. low during the monsoon season and high in the dry period. The coherence images from October 2016 to May 2017 overlaid on Google Earth are shown in the Figure 7. Aquaculture pond in Nachugunta village (shown in blue square box) has low coherence since it is filled with water in all the seasons. The coherence in mangroves was low $(0.25-0.38)$ in almost in all the seasons due to volume decorrelation. However, there was also slight variation in the coherence values of mangrove swamps (shown in white square box) depending on the season. The coherence values in the images of $25^{\text {th }}$ October 2016, $6^{\text {th }}$ November 2016, $12^{\text {th }}$ December $2016,24^{\text {th }}$ December 2016 and $17^{\text {th }}$ January 2017 were low $(0.25-0.29)$ due to the roots of the mangrove swamps withholding more water during and after the monsoon period. During summers, a comparative increase in coherence $(0.3-0.38)$ was observed during $29^{\text {th }}$ January 2017, $10^{\text {th }}$ February 2017, $11^{\text {th }}$ April 2017 and $5^{\text {th }}$ May 2017 because of evaporation of water accumulated in and around the mangrove swamps. In vernal pool, shown in black square box in Figure 7, the coherence varied from as low as 0.28 in the monsoon period to as high as 0.45 in the dry period. The feature is filled with water in the monsoon period and as a result exhibited low coherence $(0.28-0.35)$ during of $25^{\text {th }}$ October 2016, $6^{\text {th }}$ November 2016, $12^{\text {th }}$ December 2016, $24^{\text {th }}$ December 2016 and $17^{\text {th }}$ January 2017. The water dries up due to evapotranspiration in the later months- $29^{\text {th }}$ January $2017,10^{\text {th }}$ February 2017, $11^{\text {th }}$ April 2017 and $5^{\text {th }}$ May 2017 and thus the coherence values range between 0.35 and 0.45 , also low coherence values were noticed in areas where there is vegetation. High coherence values varying between 0.65 and 0.85 were observed from buildings, roads and wells in the village of Gullalamoda (shown in pink square). The agricultural fields (shown in yellow square) nearby the village of Lankevanidibba showed varying coherence between 0.35 and 0.6 .

\subsection{PS Coherence Map}

The Permanent Scatter (PS) coherence map obtained after Atmospheric Phase Screen (APS) removal is shown in Figure 8.

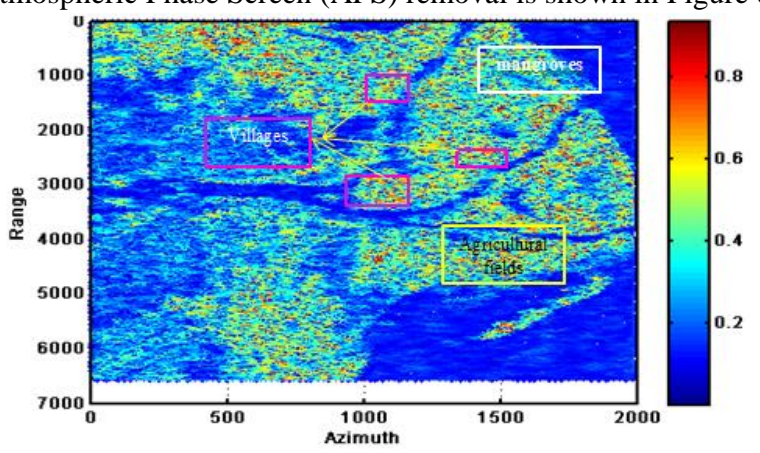

Figure 8: PS Coherence Map

The coherence bar indicates areas showing low to high coherence whose values range between 0 and 1 . The region in Yellow Rectangle shows high coherence from 0.8 to 0.9 . These strong coherence values are from PS points indicated in red. These PS points having high coherence are the permanent structures in villages (Pink Rectangle) like roads, wells, buildings that have high coherence. Different features- 
mangroves, agricultural fields and the villages are shown in figure 22. The coherence ( 0.2 to 0.35$)$ is low in mangroves (White Rectangle). Coherence values are as high has 0.58 to 0.75 in the villages within the InSAR data product. The coherence in agricultural fields ranges from low to medium, i.e. from 0.15 to 0.38 .

\subsection{PS Integrated Cumulative Displacement Map}

The overall displacement obtained in Krishna Delta that occurred between October 2016 and June 2017 was obtained by generating an integrated cumulative displacement map.

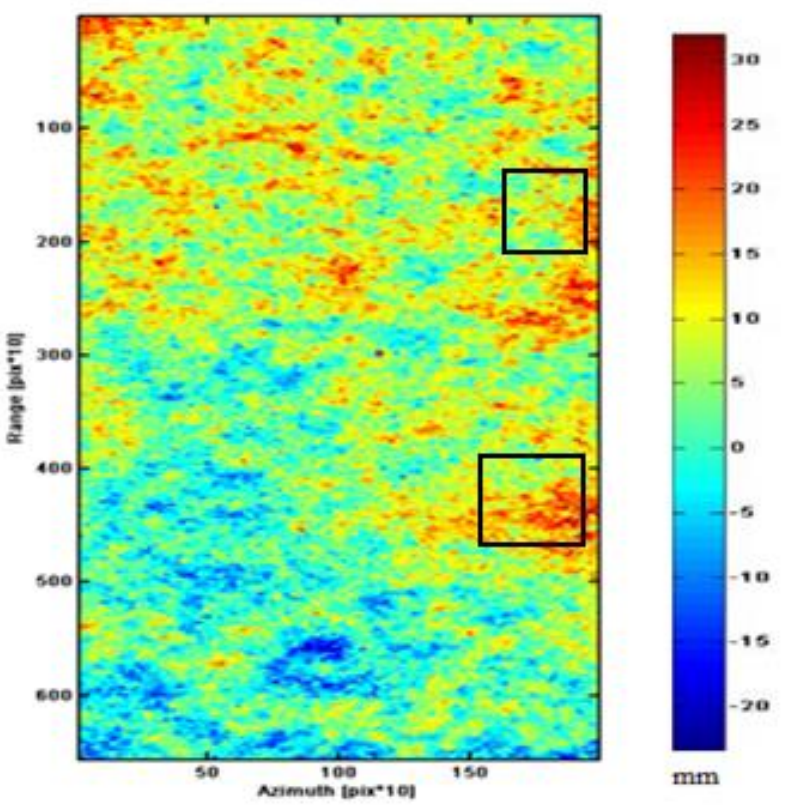

Figure 9: Integrated Cumulative Displacement Map

The integrated cumulative displacement map is shown in Figure 9. The map highlights the areas subjected to displacement during the nine-month period. The colour bar represents the maximum and minimum range of displacement values. Minimum displacement is represented in blue and maximum displacement in red as shown in colour bar. The overall displacement varied from -25 to $25 \mathrm{~mm}$. The displacement was observed in conjunction with the soil erosion and deposition that has taken place in Krishna delta. Negative values indicate that erosion has taken place and positive values indicate deposition. The regions shown in Black Square are mangrove swamps and marshy lands where there is more accumulation of sediments, i.e. deposition has taken place. The roots of mangroves help in preventing erosion. The regions where erosion has taken place are agricultural lands and aquaculture ponds nearby the mangrove vegetation. The displacement values obtained can be correlated with the coherence obtained over the same area as shown in Figure 7.

\section{CONCLUSION}

The present study explored the potential of PsInSAR technique to overcome the shortcoming of decorrelation and Atmospheric Phase Screen to identify the Permanent Scatter Candidates based on the Amplitude Stability index of these coherent points. The PSCs identified helped in estimating the coherence of deltaic features during the wet and dry periods using 13 Interferometric C-band datasets. The coherence images obtained were overlaid on Google Earth to show the variation in coherence over different features during monsoon and summer seasons. As observed in the PS coherence map, aquaculture ponds exhibited low coherence in all seasons. Mangroves exhibited coherence varying from 0.25 to 0.38 owing to volume decorrelation. Relatively low coherence was observed in Wet period and a slight increase in coherence was observed during the summer due to evapotranspiration. Coherence values observed for vernal pools varied between 0.28 in the monsoon period and 0.45 in the dry period when there is no presence of water. The coherence in urban villages was high owing to the presence of permanent features such as buildings, roads. The integrated displacement map helped to identify areas where erosion and deposition has occurred.

\section{ACKNOWLEDGEMENTS}

The authors would like to sincerely thank European Space Agency (ESA) for providing Interferometric datasets of Sentinel-1 C band and SARPROZ software team for providing the license to process the datasets. We are grateful to Indian Institute of Remote Sensing (IIRS), ISRO, India, and Centre for Space Science and Technology Education in Asia and the Pacific (CSSTEAP), Dehradun, India for providing good infrastructure to carry out this research work..

\section{REFERENCES}

Anthony, E. J., Brunier, G., Besset, M., Goichot, M., Dussouillez, P., \& Nguyen, V. L. 2015. Linking rapid erosion of the Mekong River delta to human activities. $\begin{array}{llll}\text { Scientific Reports, } & \text { 5, } & 14745 .\end{array}$ https://doi.org/10.1038/srep14745

Bamler, R., \& Hartl, P. 1998. Synthetic aperture radar interferometry. Inverse Problems, 14(4), R1-R54. https://doi.org/10.1088/0266-5611/14/4/001

Erban, L. E., Gorelick, S. M., \& Zebker, H. A. 2014 Groundwater extraction, land subsidence, and sea-level rise in the Mekong Delta, Vietnam. Environmental $\begin{array}{lll}\text { Research Letters, } & 9(8), & 84010 .\end{array}$ https://doi.org/10.1088/1748-9326/9/8/084010

Farooqui. 2010. Salt water intrusion, metal accumulation and mangroves along the Pednapatnam , Machlipatnam coastline. Journal of Applied Geochemistry, 12(1), 122 138.

Gamage, N., \& Smakhtin, V. 2009. Do river deltas in east India retreat? A case of the Krishna Delta. Geomorphology, 103(4), https://doi.org/10.1016/j.geomorph.2008.07.022

Gonnuru, P., \& Kumar, S. 2018. C-band SAR interferometry for change detection analysis in Krishna River Delta. In 2018 3rd International Conference on Microwave and Photonics (ICMAP) (pp. 1-2). https://doi.org/10.1109/ICMAP.2018.8354534

Gonnuru, P., \& Kumar, S. 2018. Remote Sensing Applications : Society and Environment PsInSAR based land subsidence estimation of Burgan oil fi eld using TerraSAR-X data. Remote Sensing Applications: Society and Environment, 9(September 2017), 17-25. https://doi.org/10.1016/j.rsase.2017.11.003

Grandin. 2015. Interferometric Processing of SLC Sentinel-1 TOPS Data. In Proceedings of ESA Fringe Workshop.

Hall-Atkinson, C., \& Smith, L. C. 2001. Delineation of delta ecozones using interferometric SAR phase coherence: Mackenzie River Delta, N.W.T., Canada. Remote Sensing of Environment, 78(3), 229-238. 
https://doi.org/https://doi.org/10.1016/S00344257(01)00221-8

Hartl, R. B. and P. 1998. Synthetic aperture radar interferometry. Inverse Problems, 14(4), R1. Retrieved from http://stacks.iop.org/0266-5611/14/i=4/a=001

Hooper, A. J., Segall, P., \& Zebker, H. (2006). Persistent scatter radar interferometry for crustal deformation studies and modeling of volcanic deformation. the Department of Geophysics.

Hooper, A., Segall, P., \& Zebker, H. 2007. Persistent scatterer interferometric synthetic aperture radar for crustal deformation analysis, with application to Volca' n Alcedo , Gala ' pagos. Journal of Geophysical Research, 112, 1-21. https://doi.org/10.1029/2006JB004763

Lee, J.-S., \& Pottier, E. 2009. Polarimetric radar imaging: from basics to applications. CRC Press.

Moreira, A., Prats, P., Younis, M., Krieger, G., Hajnsek, I., \& Papathanassiou, K. 2013. A Tutorial on Synthetic Aperture Radar. IEEE Geoscience and Remote Sensing Magazine, (march), 1-43. https://doi.org/10.1109/MGRS.2013.2248301

Nageswara Rao, K., Saito, Y., Nagakumar, K. C. V, Demudu, G., Basavaiah, N., Rajawat, A. S., ... Nakashima, R. 2012. Holocene environmental changes of the Godavari Delta, east coast of India, inferred from sediment core analyses and AMS 14C dating. Geomorphology, 175176 , $163-175$. https://doi.org/10.1016/j.geomorph.2012.07.007

Perissin, D. 2016. Interferometric SAR Multitemporal Processing: Techniques and Applications. https://doi.org/10.1007/978-3-319-47037-5_8

Wang, H., Wright, T. J., Yu, Y., Lin, H., Jiang, L., Li, C., \& Qiu, G. 2012. InSAR reveals coastal subsidence in the Pearl River Delta, China. Geophysical Journal International, 191(3), 1119-1128. Retrieved from http://dx.doi.org/10.1111/j.1365-246X.2012.05687.x

Yague-Martinez, N., Prats-Iraola, P., Gonzalez, F. R., Brcic, R., Shau, R., Geudtner, D., ... Bamler, R. 2016. Interferometric Processing of Sentinel-1 TOPS Data. IEEE Transactions on Geoscience and Remote Sensing, 54(4), 220-2234 https://doi.org/10.1109/TGRS.2015.2497902 